Organo- and

Biocatalysis

\title{
Organocatalytic Asymmetric Claisen Rearrangement
}

Key words

Claisen

rearrangement

chiral guanidinium salts

H-bonding catalysts

General strategy of the guanidinium salt-catalyzed Claisen rearrangement:

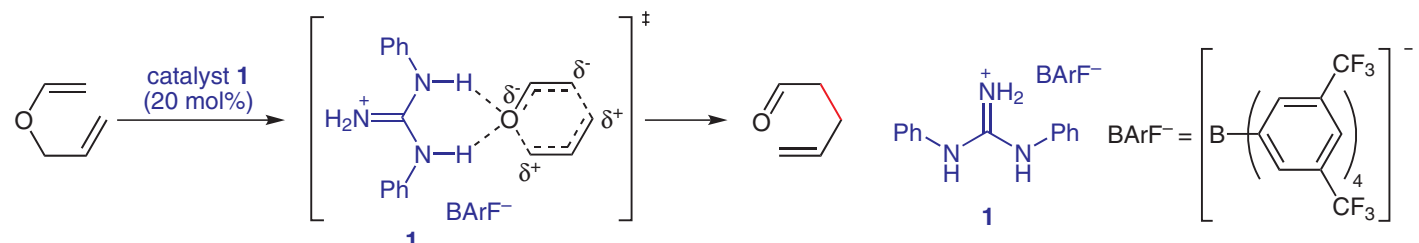

Selected examples:

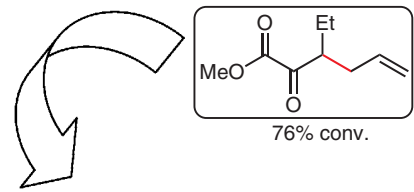<smiles>CC(=CC(CC=O)c1ccccc1)[N+](=O)[O-]</smiles><smiles>C=C1CCCOC1CC=O</smiles>

$72 \%$ conv.<smiles>CC(C)=CCc1ccccc1O</smiles>

Asymmetric variant with ester-substituted allyl vinyl ethers 2:

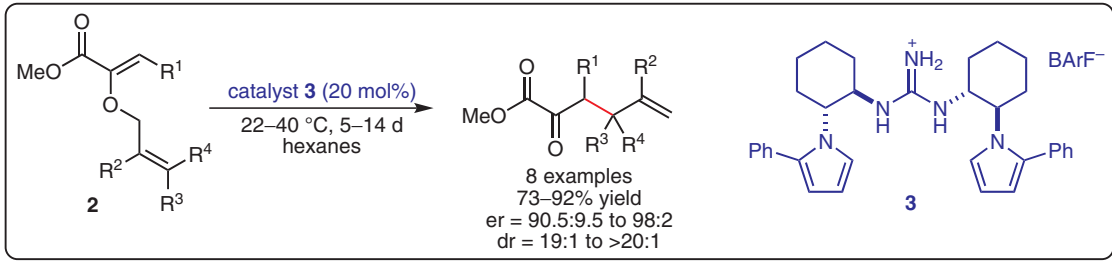

Selected examples:

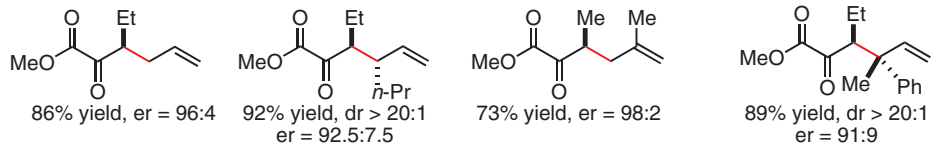

Significance: Catalysis of the Claisen rearrangement by simple guanidinium salts such as $N, N^{\prime}$ diphenylguanidinium salt $\mathbf{1}$ is reported. A broad variety of substituted allyl vinyl ethers (see selected examples) were suitable substrates for this interesting transformation. Moreover, highly enantioselective Claisen rearrangements of estersubstituted allyl vinyl ethers 2 have been achieved using $C_{2}$-symmetric guanidinium salt $\mathbf{3}$ as the catalyst. Other types of substrates failed to give satisfying results in the asymmetric variant. The weakly coordinating counterion $\mathrm{BArF}^{-}$was found to be crucial for catalytic activity of the respective guanidinium salt.

SYNFACTS Contributors: Benjamin List, Corinna Reisinger Synfacts 2008, 9, 0987-0987 Published online: 22.08.2008 DoI: 10.1055/s-2008-1078674; Reg-No.: B06908SF
Comment: (Thio)ureas constitute a privileged class of $\mathrm{H}$-bonding catalysts (see Review below). However, in catalytic Claisen rearrangements only modest rate accelerations have been realized by means of this catalyst class (see, for example: M. Hiersemann, T. Strassner and co-workers J. Org. Chem. 2007, 72, 4001). Although guanidinium BArF species exhibit similar $p K_{a}$ values as $N, N^{\prime}$ diarylthioureas, they possess superior catalytic activity in this transformation. This work complements the metal-catalyzed asymmetric Claisen rearrangement developed by the Hiersemann group (Angew. Chem. Int. Ed. 2001, 40, 4700).

Review: M. S. Taylor, E. N. Jacobsen Angew. Chem. Int. Ed. 2006, 45, 1520-1543. 